\title{
Correction to: Seminal Plasma and Serum Afamin Levels Are Associated with Infertility in Men with Oligoasthenoteratozoospermia
}

Rocio Nuñez-Calonge ${ }^{1}$ - Susana Cortes ${ }^{2}$ Pedro Caballero Peregrín ${ }^{1} \cdot$ Luis Miguel Gutierrez Gonzalez $^{3}$. Roman Kireev ${ }^{4}$

Published online: 22 February 2021

(C) Society for Reproductive Investigation 2021

Correction to: Reproductive Sciences. https://doi.org/10.1007/s43032-020-00436-8

This article was updated to correct errors In Table 1 and References 7 and 27.

Publisher's Note Springer Nature remains neutral with regard to jurisdictional claims in published maps and institutional affiliations.

The online version of the original article can be found at https://doi.org/ 10.1007/s43032-020-00436-8

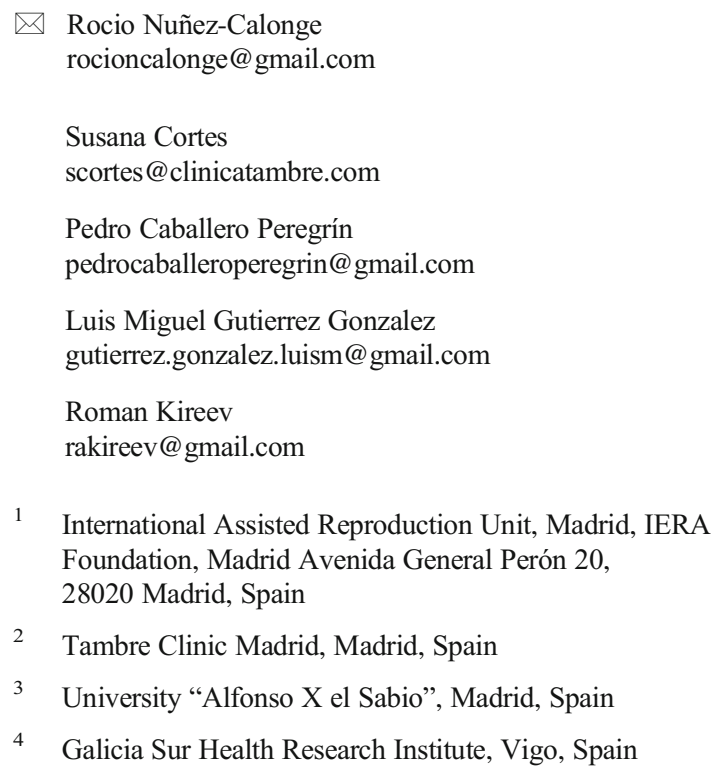

4 Galicia Sur Health Research Institute, Vigo, Spain 